(c) American Dairy Science Association, 2006.

\title{
Decreased Insulin Response in Dairy Cows Following a Four-Day Fast to Induce Hepatic Lipidosis
}

\author{
S. Oikawa* and G. R. Oetzel $\dagger^{1}$ \\ *Department of Large Animal Clinical Science, School of Veterinary Medicine, Rakuno Gakuen University, Ebetsu, Hokkaido, Japan 069-8501 \\ †Department of Medical Sciences, School of Veterinary Medicine, University of Wisconsin, Madison 53706
}

\begin{abstract}
Negative energy balance has been implicated in the development of fatty liver, insulin resistance, and impaired health in dairy cows. A 4-d fasting model previously was reported to increase liver triglycerides more than 2.5 -fold. The purpose of the present study was to evaluate insulin response in this fasting model. Nonlactating, nonpregnant Holstein cows were fasted for $4 \mathrm{~d}$ (6 cows) or fed continuously as control cows (4 cows). Samples were collected $5 \mathrm{~d}$ before fasting, during fasting, and immediately after the 4-d fast, $8 \mathrm{~d}$ after the fast, and $16 \mathrm{~d}$ after the fast. Fasted cows had greater liver triglyceride content ( $49.4 \mathrm{vs} .16 .2 \mathrm{mg} / \mathrm{g}$, wet-weight basis) at the end of the fasting period compared with control cows. Fasted cows also had increased plasma nonesterified fatty acid (NEFA) concentrations (1.24 vs. $0.21 \mathrm{mmol} / \mathrm{L}$ ) and increased plasma $\beta$-hydroxybutyrate (BHBA) concentrations at the end of the fasting period. Liver triglyceride, plasma NEFA, and plasma BHBA in fasted cows returned to prefasting concentrations by the end of the experiment. Plasma glucose concentrations were not affected by fasting. Plasma insulin concentrations were decreased ( 6.3 vs. $14.1 \mu \mathrm{U} / \mathrm{mL}$ ) and insulin-stimulated blood glucose reduction was decreased ( 24.9 vs. $48.6 \%$ ) in the fasted cows compared with control cows at the end of the fast, indicating reduced insulin response. Insulin response was negatively correlated with plasma NEFA and liver triglycerides. Decreased insulin response may be an important complication of negative energy balance and hepatic lipidosis.
\end{abstract}

Key words: dairy cow, fasting model, hepatic lipidosis, insulin response

\section{INTRODUCTION}

Negative energy balance (NEB), decreased DMI, stress, hormonal imbalance, and parturition are im-

Received June 22, 2005.

Accepted March 6, 2006

${ }^{1}$ Corresponding author: groetzel@wisc.edu portant risk factors for hepatic lipidosis in dairy cattle (Oikawa et al., 1997; Mohamed et al., 2004). Reduction in DMI, especially during the final week before calving, is a crucial factor related to the development of hepatic lipidosis (Bertics and Grummer, 1999). Hepatic lipidosis increases risk for periparturient diseases (Oikawa et al., 1997), particularly for periparturient ketosis (Herdt and Gerloff, 1999). Periparturient ketosis may be characterized by hyperglycemia and hyperinsulinemia, presumably because of insulin resistance (Holtenius, 1993), and is categorized as type 2 ketosis because of its similarities to type 2 diabetes mellitus (Holtenius and Holtenius, 1996). Hyperglycemia and hyperinsulinemia are not consistent findings in cows with periparturient ketosis; however, they may have been present earlier in the course of the disease and contributed to its development (Herdt, 2000).

Insulin resistance is defined as a state in which normal concentrations of insulin produce a less than normal biological response (Kahn, 1978). States of insulin resistance may consist of decreased insulin sensitivity (i.e., a high insulin dose required to produce a halfmaximal response in blood glucose concentration), decreased insulin responsiveness (i.e., a low maximal blood glucose response to a high dose of insulin), or a combination of both decreased insulin sensitivity and responsiveness. Different mechanisms may lead to decreased insulin sensitivity or decreased insulin responsiveness (Kahn, 1978).

States of insulin resistance have not been well characterized in dairy cattle. The gold standard test for diagnosing insulin resistance in human medicine is the hyperinsulinemic-euglycemic clamp (Monzillo and Hamdy, 2003). The hyperinsulinemic-euglycemic clamp has been used in small-scale studies to study metabolism in dairy cattle (Holtenius et al., 2000; Mashek et al., 2001). Because of practical limitations, this method has not been used in larger studies, and it has not been used to determine whether spontaneous insulin resistance is present in dairy cattle. Insulin responsiveness may be evaluated by insulin tolerance tests, which are more practical to conduct. Insulin tolerance tests involve intravenously administering a fixed bolus of insulin (about $0.1 \mathrm{U} / \mathrm{kg}$ ) and then measuring the 
plasma glucose decrement during a 60 -min period (Monzillo and Hamdy, 2003). Ohtsuka et al. (2001) reported decreased insulin response (blood glucose response $30 \mathrm{~min}$ after an i.v. bolus of $0.05 \mathrm{U} / \mathrm{kg}$ insulin) in dairy cows with spontaneous fatty liver. Many of these cows had severe hepatic lipidosis, and insulin response decreased with increasing severity of hepatic lipidosis (Ohtsuka et al., 2001). Kushibiki et al. (2001) reported decreased insulin response (blood glucose response 0 to $240 \mathrm{~min}$ after an i.v. bolus of $0.2 \mathrm{U} / \mathrm{kg}$ insulin) in Holstein steers following prolonged treatment with tumor necrosis factor- $\alpha$. Tumor necrosis factor- $\alpha$ has been associated with hepatic lipidosis. Ohtsuka et al. (2001) reported more than 3-fold greater concentrations of tumor necrosis factor- $\alpha$ in dairy cows with severe hepatic lipidosis than cows with mild fatty liver.

Fasting is an alternative method to induce hepatic lipidosis (Mohamed et al., 2004; Mashek et al., 2005). Fasting causes NEB and accelerated mobilization of NEFA from adipose tissues to the liver. Fat accumulates in the liver when hepatic fatty acid uptake and esterification exceed the capacity of the liver to either oxidize fatty acids or export them as very low density lipoproteins (Gerloff et al., 1986). Fasting increased liver triglycerides (TG) more than 2.5-fold and reduced hepatic extraction of bile acids (Mohamed et al., 2004). Insulin response has not been evaluated in a fasting model.

The purposes of this study were to determine whether insulin response is decreased during a 4-d fasting model, and to evaluate the relationship between insulin response and other metabolic changes that accompany fasting.

\section{MATERIALS AND METHODS}

\section{Cows}

Twenty Holstein cows were purchased from a commercial market. All cows were 3 to 5 yr old, nonpregnant, and nonlactating. All cows had a BCS between 3.25 and 3.50 based on the 5-point scale (Edmonson et al., 1989). Cows were evaluated for health problems by physical examination and blood test results. Eleven cows were selected from this group of 20 based on normal physical examination findings and normal blood test results for packed cell volume, white blood cell count, serum total protein concentration, and serum globulin-to-albumin ratio (Kaneko, 1997). Cows were allotted randomly (by coin toss) to a fasted $(\mathrm{n}=6)$ or control group $(n=5)$. One cow in the control group was injured during the experiment and was removed from the study. No data from this cow were included in the analysis.
Cows were maintained in individual tie stalls. Their care adhered to the laboratory animal control guidelines of Rakuno Gakuen University. Before and after fasting, cows were fed a concentrate mix at the rate of $0.5 \%$ of BW on a DM basis twice daily (0800 and 1700 h) and a constant amount of grass hay (about $0.5 \%$ of BW/d, DM basis). Feed refusals were negligible throughout the trial. A concentrate mix contained approximately $18 \% \mathrm{CP}, 2 \%$ crude fat, and $1.69 \mathrm{Mcal}$ of $\mathrm{NE}_{\mathrm{L}} / \mathrm{kg}$ (DM basis). Water and free-choice minerals were available ad libitum for all cows throughout the experimental period. To reduce risk of gastrointestinal dysfunction upon refeeding, the concentrate mix was gradually reintroduced to the fasted cows for the first $2 \mathrm{~d}$ after the end of the fasting period.

\section{Experimental Procedure and Blood Sampling}

The duration of the experiment was $26 \mathrm{~d}$. The experiment consisted of 3 periods: prefasting, fasting, and postfasting. The beginning of the prefasting period was designated as $\mathrm{d}-5$. The fasting period started on $\mathrm{d} 0$ and ended on $\mathrm{d} 4$. The postfasting period started on $\mathrm{d}$ 4 and continued until d 20. The BCS and BW of each cow were determined at approximately $0700 \mathrm{~h}$ on $\mathrm{d}-3$, 4,12 , and 20 . The BCS was recorded as the average of 2 scores assigned independently by 2 evaluators using a 5-point scale (Edmonson et al., 1989). Evaluators could not be blind to treatment assignments because cows in the fasted group had visually apparent changes in behavior and abdominal fill during the fasting period.

Deep catheters (14 gauge $\times 30 \mathrm{~cm}$ ) fitted with extension tubes (Togomedikit, Tokyo, Japan) were placed in both jugular veins of each cow $1 \mathrm{~d}$ before the start of the prefasting period. All catheters were flushed twice daily with a $3.8 \%$ sodium citrate solution. Catheters that lost patency were replaced; this happened approximately once for each cow during the trial.

Blood was collected for NEFA, BHBA, and glucose determinations on $\mathrm{d}-5,-3,-1,0,1,2,3,4,5,6,8,10$, $12,14,16,18$, and 20 . Blood was collected for insulin determinations on $d-3,1,4,10$, and 20 . Blood samples were collected via jugular catheter into a plastic syringe at about $0730 \mathrm{~h}$. Blood was then transferred into heparinized tubes (for NEFA, BHBA, and insulin analyses) and into tubes containing $\mathrm{NaF}$ for blood for glucose analysis. Tubes were placed in ice immediately after collection and centrifugation $(2,500 \times g$ for $15 \mathrm{~min}$ at $4^{\circ} \mathrm{C}$ ) was started within 10 min of collection. Separated plasma was immediately frozen and stored at $-80^{\circ} \mathrm{C}$ until analysis.

\section{Insulin Tolerance Test}

Insulin-stimulated blood glucose response (ISBGR) was determined on $\mathrm{d}-3,4,12$, and 20 using a modifica- 
tion of the protocol described by Ohtsuka et al. (2001). Blood samples were collected at -10 and 0 min for baseline blood glucose analyses, and the average value was recorded. Immediately after the 0 -min sample was collected, cows were given a bolus i.v. dose of insulin $(0.05$ U/kg; Novolin R; Novo Nordisk Pharma Ltd., Tokyo, Japan) through the opposite jugular catheter. A blood sample was collected 30 min later. Blood samples for the glucose assays used in the ISBGR determinations were collected and processed as described previously for the blood glucose tests. The ISBGR was calculated by the formula: ISBGR $(\%)=[(\mathrm{G} 0-\mathrm{G} 1) / \mathrm{G} 0] \times 100$, where G0 is the baseline glucose concentration and G1 is the glucose concentration $30 \mathrm{~min}$ after insulin infusion.

\section{Liver Specimens}

Liver biopsies were obtained on $\mathrm{d}-3,4,12$, and 20 . Biopsy samples were collected at $1100 \mathrm{~h}$ (approximately $3 \mathrm{~h}$ after the completion of the ISBGR evaluation), which allowed sufficient time for blood glucose to return to normal concentrations. Cows were sedated with i.v. xylazine $(0.07 \mathrm{mg} / \mathrm{kg}$ of BW) before sampling. The biopsy area was surgically prepared and infiltrated with $10 \mathrm{~mL}$ of $2 \%$ procaine hydrochloride. Placement of the biopsy needle to collect the liver tissue was guided by ultrasonography. Liver biopsy samples (about $0.4 \mathrm{~g}$ per sample) were rinsed in sterile saline solution, frozen in liquid $\mathrm{N}_{2}$, and stored at $-80^{\circ} \mathrm{C}$.

\section{Blood Analyses}

Plasma concentrations of NEFA, BHBA, and glucose were determined using a clinical biochemistry autoanalyzer (BioMajesty JCA-BM 2250; JEOL Ltd., Tokyo, Japan). Plasma NEFA was determined enzymatically using a commercial kit (N-assay NEFA; Nittobo Medical Ltd, Tokyo, Japan) according to the procedure of Okabe and Uji (1999). Plasma BHBA was determined enzymatically using a commercial kit (3-OHBA-TR; Kishimoto Clinical Laboratory, Sapporo, Japan) according to the procedure of Hidaka (1999). Plasma glucose was determined enzymatically using a commercial kit (GLU-TR; Kishimoto Clinical Laboratory) according to the procedure of Ono (1999). Plasma insulin concentration was measured by radioimmunoassay (Itoh et al., 1997). Intra-assay coefficient of variation for the plasma insulin determinations was $4.8 \%$. Liver TG content was determined on a wet basis by colorimetric assay (Snyder and Stephens, 1959).

\section{Statistical Analyses}

Effects of fasting on blood constituents were analyzed as repeated measures using the MIXED procedures in
SAS (SAS Institute, 1999). Cow was included as a random effect in the model, and effects of treatment (fasted vs. control), day, and treatment $\times$ day interactions were evaluated. Covariance was structured as spatial powers; this approach resulted in the lowest Akaike information criterion values (Akaike, 1974) compared with unstructured and compound symmetry approaches. Residual plots were evaluated for heteroscedasticity of the residual plots, and different data transformations were evaluated and applied as needed. A $\log _{10}$ transformation was applied to BW, liver TG, NEFA, insulin, and BHBA data. Other outcomes (BCS, glucose, and ISBGR) did not require transformation. Least squares means and standard errors presented in the results and figures are from untransformed data using the final models. Standard errors of the means were calculated for each treatment and pooled by day. Because the study included many days of comparisons for fasted and control cows, $P$-values were adjusted according to Bonferroni's inequalities (Snedecor and Cochran, 1989).

Correlations between study outcomes were calculated for data collected on $\mathrm{d} 4$ (the last day of the fasting period). Some of the study outcomes on d 4 failed tests for the assumption of normal distribution, so correlation analysis was done with Spearman rank-order correlation coefficients (Snedecor and Cochran, 1989).

\section{RESULTS}

Fasted cows lost about 8\% of their BW (from 653 to $600 \mathrm{~kg}$ ) by the end of the 4-d fast. The BW of the fasted cows $(600 \pm 17 \mathrm{~kg})$, however, did not differ from that of control cows $(654 \pm 21 \mathrm{~kg})$ at the end of the fasting period (d 4). Body condition scores of fasted cows on d 4 were decreased $(P<0.01)$ compared with those of control cows (3.04 \pm 0.05 vs. $3.44 \pm 0.06$, respectively) at the end of the fast (Figure 1). Body condition scores did not differ between the control and fasted cows on d 12 ( $8 \mathrm{~d}$ after the end of the fast) and d 20 (16 d after the end of the fast).

Liver TG content increased $(P<0.01) 3$-fold in fasted cows compared with control cows $(49.4 \pm 4.8$ vs. $16.2 \pm$ $5.9 \mathrm{mg} / \mathrm{g}$, wet basis) by the end of the fasting period (Figure 2). Liver TG content was not greater in fasted cows by d 12 and 20 ( 8 and $16 \mathrm{~d}$ after the end of the fast, respectively).

Fasted cows had increased $(P<0.01)$ blood NEFA on d 1 through 5 compared with control cows (Figure 3a). The concentration of NEFA on $d 4$ was nearly 6 -fold greater $(1.24 \pm 0.05$ vs. $0.21 \pm 0.06 \mathrm{mmol} / \mathrm{L})$ in fasted cows compared with control cows, but was not different from NEFA concentrations in control cows by $d 6$ (the second day of refeeding the fasted cows). The pattern of increase of BHBA concentration in fasted cows was 


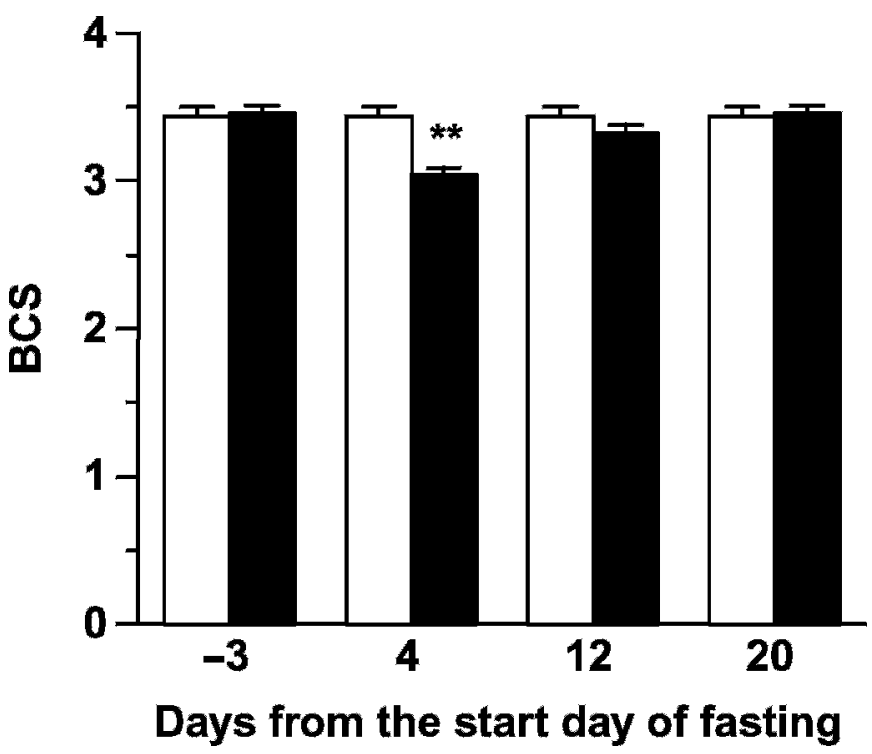

Figure 1. Body condition score (BCS) as least squares mean \pm standard error of the mean in 4 control cows (open bars) and 6 cows fasted between d 0 and 4 (solid bars). $* * P<0.01$.

similar to the pattern for NEFA (Figure 3b). Fasting increased $(P<0.01)$ BHBA on $d 3$ and $4(0.37$ and 0.44 \pm 0.02 vs. 0.23 and $0.22 \pm 0.23 \mathrm{mM}$ for fasted and control cows on $\mathrm{d} 3$ and 4 , respectively). Blood BHBA concentrations were decreased $(P<0.05)$ in the fasted cows on $\mathrm{d}$ 6 ( $2 \mathrm{~d}$ after the end of the fast).

Blood glucose concentrations were not affected by fasting and remained within the expected normal range

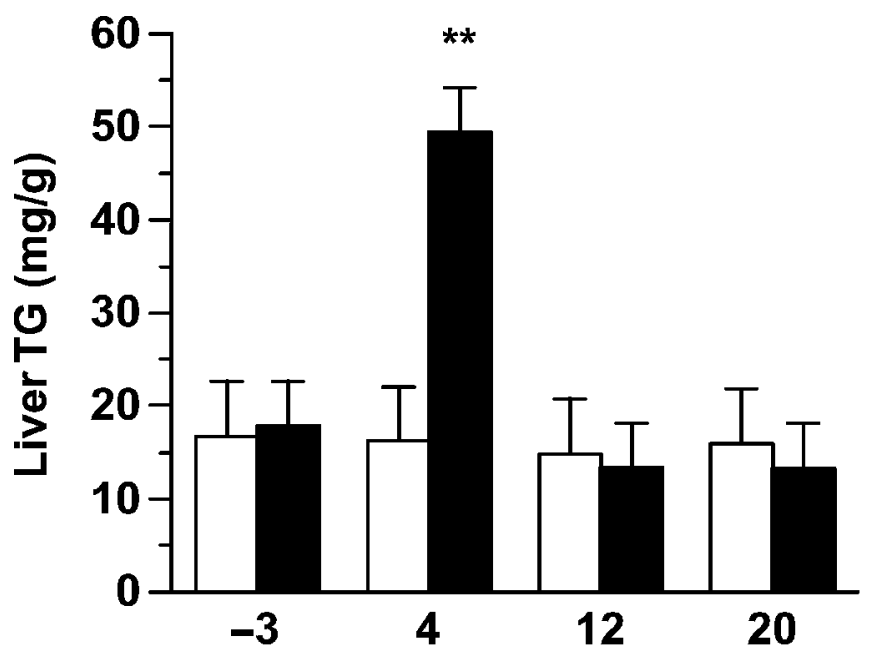

\section{Days from the start day of fasting}

Figure 2. Liver triglycerides (TG) as least squares mean \pm standard error of the mean in 4 control cows (open bars) and 6 cows fasted between $\mathrm{d} 0$ and 4 (solid bars). $* * P<0.01$.
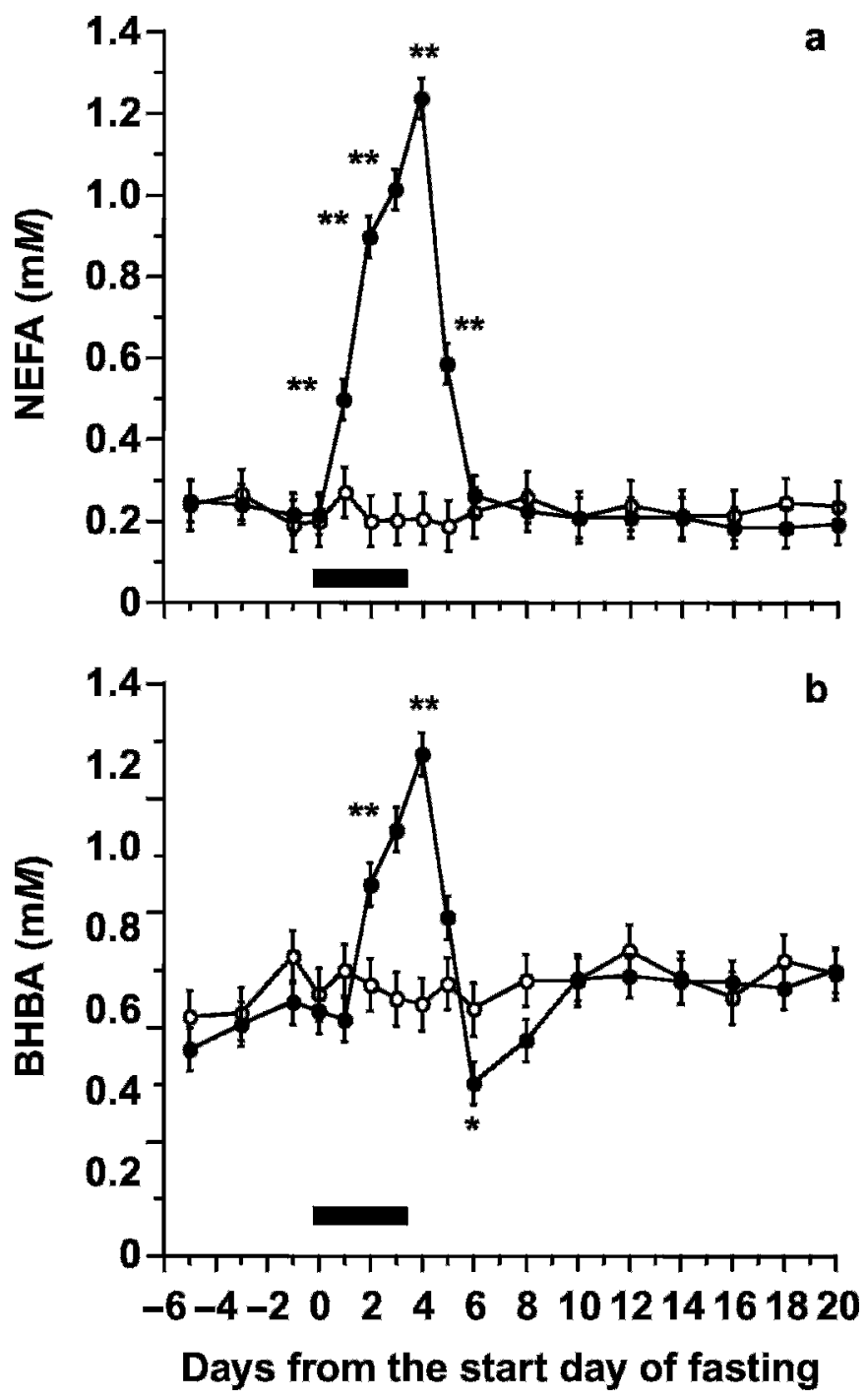

Figure 3. Plasma NEFA and BHBA as least squares mean \pm standard error of the mean in 4 control cows $(O)$ and 6 cows fasted between $d 0$ and $4(-)$. The black horizontal bar $(\longrightarrow)$ represents the fasting period. $* P<0.05, * * P<0.01$.

throughout the experiment (Figure 4a). Conversely, blood insulin concentrations were decreased $(P<0.01)$ in fasted cows on d 4 compared with control cows $(6.3$ \pm 1.7 vs. $14.1 \pm 2.0 \mu \mathrm{U} / \mathrm{mL}$, Figure $4 \mathrm{~b}$ ). Insulin concentrations did not differ between treatments on d 12 and 20 .

The ISBGR in control cows remained above $40 \%$ through the experimental period (Figure 5). Fasted cows, however, had reduced $(P<0.01)$ ISBGR on $\mathrm{d} 4$ $(24.9 \pm 3.8$ vs. $48.6 \pm 4.7 \%)$.

Spearman rank-order correlation coefficients among measured variables on d 4 are summarized in Table 1 . The ISBGR was negatively correlated $(P<0.05)$ with NEFA, liver TG, and BHBA, and was positively corre- 

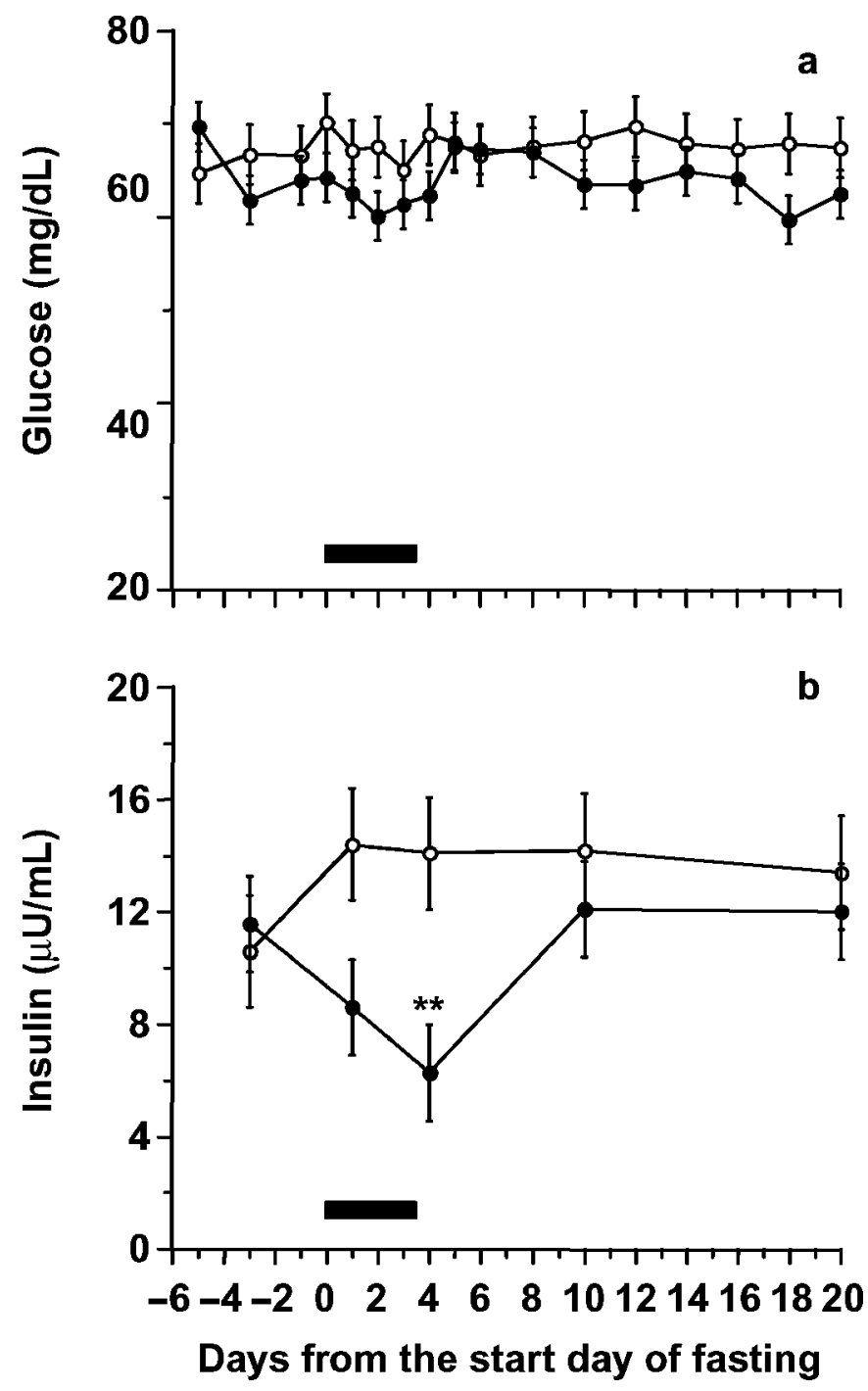

Figure 4. Plasma concentrations of glucose and insulin as least squares mean \pm standard error of the mean in 4 control cows $(\bigcirc)$ and 6 cows fasted between $\mathrm{d} 0$ and $4(\boldsymbol{)})$. The black horizontal bar ( $)$ represents the fasting period. ${ }^{* *} P<0.01$.

lated $(P<0.05)$ with insulin and BW. Glucose and BW were not correlated with ISBGR.

\section{DISCUSSION}

The exact composition of the diet consumed by cows when they were not fasting was not calculated because the nutrient composition of the grass hay was not determined. Cows started and finished the trial with no apparent change in BCS (Figure 1) or BW $(651 \pm 13 \mathrm{~kg}$ at the start of the trial vs. $649 \pm 13 \mathrm{~kg}$ at the end of the trial). These results indicate that the diets provided adequate energy.

Changes in BW, BCS, and NEFA in response to the 4-d fast were similar to those observed in other studies

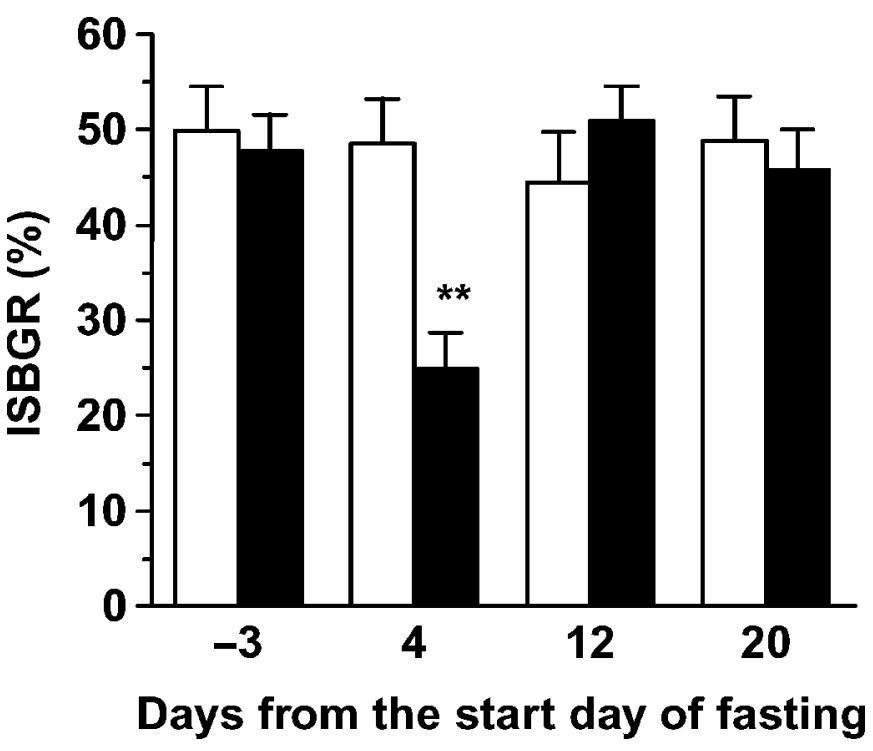

Figure 5. Insulin-stimulated blood glucose response (ISBGR) as least squares means \pm standard error of the mean in 4 control cows (open bars) and 6 cows fasted between $\mathrm{d} 0$ and 4 (solid bars). $* * P<0.01$.

(Mohamed et al., 2004; Mashek et al., 2005). The NRC (2001) estimates that cows lose $6.9 \%$ of BW when BCS decreases from 3.5 to 3.0. In this study, BCS decreased from 3.46 to 3.04 and BW decreased $8 \%$. Loss of ingesta caused by fasting could explain why the BW loss was greater in the current study compared with expected BW losses in fed animals reported by NRC.

The BCS was decreased $(P<0.05)$ in fasted cows on d 4 compared with control cows. The BCS was positively correlated $(P<0.01)$ with ISBGR and was negatively correlated with NEFA $(P<0.05)$ and BHBA $(P<0.01$; Table 1). Body weight was not correlated with any outcomes. These results indicate that rapid loss in BCS may be a useful monitor of underlying NEB, but that BW is not reliable for this purpose.

An increased liver TG content is expected in fasted cows, and the magnitude of increased liver TG in this study was similar to increases observed after a 6 -d fast (Brumby et al., 1975). None of the BHBA concentrations in the current study exceeded the cut-point of $>1.40$ $\mathrm{m} M$ described as the threshold for subclinical ketosis in early-lactation dairy cows (Duffield, 2000). Thresholds for subclinical ketosis for nonlactating cows have not been defined. Blood ketone concentrations in the current study were not as high as those observed in field studies for subclinical ketosis in early-lactation cows (Oetzel, 2004). Several factors may explain this difference. First, nonlactating cows are less susceptible to the developing ketonemia than are cows in early lactation. Second, fasting for only $4 \mathrm{~d}$ may not be enough time to induce ketogenesis. Fasting for $6 \mathrm{~d}$ (Baird et 
Table 1. Spearman rank-order correlation coefficients among values measured at the end of a 4-d fast for 10 nonpregnant, nonlactating Holstein cows

\begin{tabular}{llllllll}
\hline Variables & NEFA & Liver TG & BHBA & BW & BCS & Glucose & Insulin \\
\hline ISBGR $^{2}$ & $-0.733^{*}$ & $-0.721^{*}$ & $-0.818^{* *}$ & 0.467 & $0.829^{* *}$ & 0.248 & $0.736^{*}$ \\
Insulin & -0.578 & -0.578 & $-0.650^{*}$ & 0.468 & $0.709^{*}$ & $0.699^{*}$ & \\
Glucose & -0.333 & -0.164 & -0.248 & 0.612 & 0.428 & & \\
BCS & $-0.763^{*}$ & $-0.842^{* *}$ & $-0.829^{* *}$ & 0.618 & & & \\
BW & -0.358 & -0.430 & -0.588 & & & & \\
BHBA & $0.709^{*}$ & $0.842^{* *}$ & & & & & \\
Liver TG & $0.855^{* *}$ & & & & & & \\
\hline
\end{tabular}

${ }^{1}$ Liver TG $=$ liver triglycerides.

${ }^{2}$ ISBGR $=$ insulin-stimulated blood glucose response.

$* P<0.05 ; * * P<0.01$.

al., 1979) caused a much larger BHBA response in nonlactating cows, similar to BHBA concentrations observed in spontaneously ketotic cows. Veenhuizen et al. (1991) noted that the first response observed during a ketosis induction protocol in early-lactation cows was increased blood NEFA. The second response was increased liver TG. Increased blood BHBA concentration was the third response, and this began only after blood NEFA and liver TG concentrations had already risen. These findings indicate that a longer fasting period may have increased BHBA concentrations.

The reduction in blood BHBA in cows $2 \mathrm{~d}$ after the end of the fast could be explained by increased insulin after refeeding, which would be expected to reduce blood ketones. However, blood insulin was not measured from the end of the fast until $6 \mathrm{~d}$ later (d 10) in the current study.

Baseline blood glucose concentrations measured at $-10 \mathrm{~min}$ and at $0 \mathrm{~min}$ before the insulin tolerance testing were virtually identical (data not shown) for each test and for every cow. These data indicate that cows were well acclimated to blood sampling via the jugular catheters and apparently did not experience a stress response (which could increase the blood glucose concentration) when blood samples were collected.

The insulin tolerance test used in this study evaluated the blood glucose concentration at a single time point after insulin administration. Data from previous reports indicate that the average time to nadir for the plasma glucose concentration consistently occurs approximately $30 \mathrm{~min}$ after i.v. insulin administration, even when different insulin formulations and doses are administered (Chilliard and Ottou, 1995; Lemosquet et al., 1997; Baumgard et al., 2002). Individual cows may reach blood glucose nadir at different times. Therefore, the current protocol is less accurate than measuring blood glucose every $5 \mathrm{~min}$ for $60 \mathrm{~min}$ after insulin dosing and then calculating the slope of the linear decline in blood glucose as described by Monzillo and Hamdy (2003). In the current study, the magnitude of the effect of fasting on ISBGR was almost 2-fold and was highly significant $(P=0.003$ after adjustment for Bonferroni's inequalities).

Blood NEFA was negatively correlated $(P<0.05)$ with ISBGR on $\mathrm{d} 4$, indicating that NEFA may play a role in reducing insulin responsiveness. Other studies have associated increased NEFA with changes in insulin metabolism. Strang et al. (1998) reported that exogenous NEFA reduced insulin clearance in bovine hepatocytes. Elevated NEFA increased the risk for insulin resistance in Zucker diabetic fatty rats (Lee et al., 1994). Increased NEFA has also been reported to cause $\beta$-cell apoptosis in Zucker diabetic fatty rats (Shimabukuro et al., 1998), and prolonged elevation of plasma NEFA can desensitize the insulin secretory response to glucose in rats (Mason et al., 1999). Relationships between NEFA and insulin resistance in dairy cattle warrant further investigation.

\section{CONCLUSIONS}

A 4-d fasting model increased plasma NEFA, increased liver TG, and reduced insulin responsiveness in nonlactating dairy cows. This model may be useful in studying the pathogenesis of fatty liver and insulin response in dairy cattle. Decreased insulin response was associated with increased plasma NEFA, greater liver TG, and decreased BCS. Decreased insulin responsiveness may be an important aspect of hepatic lipidosis in dairy cows following rapid loss in BCS.

\section{ACKNOWLEDGMENTS}

The authors gratefully thank Kazuaki Sasaki and Atsushi Nitanai for assistance in data collection; Nick Keuler for statistical advice; and Tom Bennett for assistance in data management and statistical analysis. Financial support for this research was provided by a Grant-in-Aid for Science Research (14560253) from the Ministry of Education, Science, and Culture of Japan. 


\section{REFERENCES}

Akaike, H. 1974. A new look at the statistical model identification. IEEE Trans. Automatic Control 19:716-723.

Baird, G. D., R. J. Heitzman, I. M. Reid, H. W. Symonds, and M. A. Lomax. 1979. Effects of food deprivation on ketonaemia, ketogenesis and hepatic intermediary metabolism in the non-lactating dairy cow. Biochem. J. 178:35-44.

Baumgard, L. H., B. A. Corl, D. A. Dwyer, and D. E. Bauman. 2002. Effects of conjugated linoleic acids (CLA) on tissue response to homeostatic signals and plasma variables associated with lipid metabolism in lactating dairy cows. J. Anim. Sci. 80:1285-1293.

Bertics, S. J., and R. R. Grummer. 1999. Effects of fat and methionine hydroxy analog on prevention or alleviation of fatty liver induced by feed restriction. J. Dairy Sci. 82:2731-2736.

Brumby, P. E., M. Anderson, B. Tuckley, J. E. Storry, and K. G. Hibbit. 1975. Lipid metabolism in the cow during starvationinduced ketosis. Biochem. J. 146:609-615.

Chilliard, Y., and J. F. Ottou. 1995. Duodenal infusion of oil in midlactation cows. 7. Interaction with niacin on responses to glucose, insulin, and $\beta$-agonist challenges. J. Dairy Sci. 78:2452-2463.

Duffield, T. 2000. Subclinical ketosis in lactating dairy cattle. Vet. Clin. North Am. Food Anim. Pract. 16:231-253.

Edmonson, A. J., I. J. Lean, L. D. Weaver, T. Farver, and G. Webster. 1989. A body condition scoring chart for Holstein dairy cows. J. Dairy Sci. 72:68-78.

Gerloff, B. J., T. H. Herdt, and R. S. Emery. 1986. Relationship of hepatic lipidosis to health and performance in dairy cattle. J. Am. Vet. Med. Assoc. 188:845-850.

Herdt, T. H. 2000. Ruminant adaptation to negative energy balance: Influences on the etiology of ketosis and fatty liver. Vet. Clin. North Am. Food Anim. Pract. 16:215-230.

Herdt, T. H., and B. J. Gerloff. 1999. Ketosis. Pages 226-228 in Current Veterinary Therapy 4: Food Animal Practice. J. L. Howard and R. A. Smith, ed. W. B. Saunders, Philadelphia, PA.

Hidaka, H. 1999. Serum ketone bodies: Measurement and clinical significance. Nippon Rinsho 57(Suppl.):639-641.

Holtenius, P. 1993. Hormonal regulation related to the development of fatty liver and ketosis. Acta Vet. Scand. 89(Suppl.):55-60.

Holtenius, P., and K. Holtenius. 1996. New aspects of ketone bodies in energy metabolism of dairy cows: A review. J. Vet. Med. Ser. A $43: 579-587$.

Holtenius, K., K. Sternbauer, and P. Holtenius. 2000. The effect of the plasma glucose level on the abomasal function in dairy cows. J. Anim. Sci. 78:1930-1935.

Itoh, F., Y. Obara, H. Fuse, I. Osaka, and K. Hodate. 1997. Responses of plasma insulin, glucagons, growth hormone, and metabolites in heifers during cold and heat exposure. Anim. Sci. Technol. 68:727-734.

Kahn, C. R. 1978. Insulin resistance, insulin insensitivity, and insulin unresponsiveness: A necessary distinction. Metabolism 27:1893-1902

Kaneko, J. J. 1997. Blood analyte reference values in large animals. Pages 880-894 in Clinical Biochemistry of Domestic Animals. J. J. Kaneko, J. W. Harvey, and M. L. Bruss, ed. Academic Press, San Diego, CA.

Kushibiki, S., K. Hodate, H. Shingu, Y. Ueda, Y. Mori, T. Itoh, and Y. Yokomizo. 2001. Effects of long-term administration of recombinant bovine tumor necrosis factor- $\alpha$ on glucose metabolism and growth hormone secretion in steers. Am. J. Vet. Res. 62:794-798.

Lee, Y., H. Hirose, M. Ohneda, J. H. Johnson, J. D. McGarry, and R. H. Unger. 1994. $\beta$-Cell lipotoxicity in the pathogenesis of non- insulin-dependent diabetes mellitus of obese rats: Impairment in adipocyte- $\beta$-cell relationships. Proc. Natl. Acad. Sci. USA 91:10878-10882.

Lemosquet, S., N. Rideau, H. Rulquin, P. Faverdin, J. Simon, and R. Verite. 1997. Effects of a duodenal glucose infusion on the relationship between plasma concentrations of glucose and insulin in dairy cows. J. Dairy Sci. 80:2854-2865.

Mashek, D., S. J. Bertics, and R. R. Grummer. 2005. Effects of intravenous triacylglycerol emulsions on hepatic metabolism and blood metabolites in fasted dairy cows. J. Dairy Sci. 88:100-109.

Mashek, D. G., K. L. Ingvartsen, J. B. Andersen, M. Vestergaard, and T. Larsen. 2001. Effects of a four-day hyperinsulinemiceuglycemic clamp in early and mid-lactation dairy cows on plasma concentrations of metabolites, hormones, and binding proteins. Domest. Anim. Endocrinol. 21:169-185.

Mason, T. M., T. Goh, V. Tchipashvili, H. Sandhu, N. Gupta, G. F. Lewis, and A. Giacca. 1999. Prolonged elevation of plasma free fatty acids desensitizes the insulin secretory response to glucose in rats. Diabetes 48:524-530.

Mohamed, T., S. Oikawa, Y. Iwasaki, Y. Mizunuma, K. Takehana, D. Endoh, and T. Kurosawa. 2004. Metabolic profiles and bile acid extraction rate in the liver of cows with fasting-induced hepatic lipidosis. J. Vet. Med. A 51:113-118.

Monzillo, L. U., and O. Hamdy. 2003. Evaluation of insulin sensitivity in clinical practice and in research settings. Nutr. Rev. 61:397412

NRC (National Research Council). 2001. Page 24 in Nutrient Requirements of Dairy Cattle. 7th rev. ed. Natl. Acad. Sci., Washington, DC.

Oetzel, G. R. 2004. Monitoring and testing dairy herds for metabolic disease. Vet. Clin. North Am. Food Anim. Pract. 20:651-674.

Ohtsuka, H., M. Koiwa, A. Hatsugaya, K. Kudo, F. Hoshi, N. Itoh, H. Yokota, H. Okada, and S. Kawamura. 2001. Relationship between serum TNF activity and insulin resistance in dairy cows affected with naturally occurring fatty liver. J. Vet. Med. Sci. 63:10211025.

Oikawa, S., N. Katoh, F. Kawawa, and Y. Ono. 1997. Decreased serum apolipoprotein B-100 and A-I concentrations in cows with ketosis and left displacement of the abomasum. Am. J. Vet. Res. 58:121-125.

Okabe, H., and Y. Uji. 1999. Free fatty acid and its fractions. Nippon Rinsho 57(Suppl.):49-51.

Ono, S. 1999. Glucose. Nippon Rinsho 57(Suppl.):142-144.

SAS Institute. 1999. SAS/STAT User's Guide. Version 8 ed. SAS Institute Inc., Cary, NC.

Shimabukuro, M., Y. Zhou, M. Levi, and R. H. Unger. 1998. Fatty acid-induced $\beta$ cell apoptosis: A link between obesity and diabetes. Proc. Natl. Acad. Sci. USA 95:2498-2502.

Snedecor, G. W., and W. G. Cochran. 1989. Statistical Methods. 8th ed. Iowa State Univ. Press, Ames.

Snyder, F., and N. Stephens. 1959. A simplified spectrophotometric determination of ester groups in lipids. Biochim. Biophys. Acta 34:244-245.

Strang, B. D., S. J. Bertics, R. R. Grummer, and L. E. Armentano. 1998. Relationship of triglyceride accumulation to insulin clearance and hormonal responsiveness in bovine hepatocytes. J. Dairy Sci. 81:740-747.

Veenhuizen, J. J., J. K. Drackley, M. J. Richard, T. P. Sanderson, L. D. Miller, and J. W. Young. 1991. Metabolic changes in blood and liver during development and early treatment of experimental fatty liver and ketosis in cows. J. Dairy Sci. 74:4238-4253. 